\title{
The Bethesda system for reporting thyroid FNAC: A cytohistological correlation in a newly established institute
}

\author{
Sampa Choudhury ${ }^{1, *}$, Archana H Deshpande ${ }^{2}$, Chitrawati B Gargade ${ }^{3}$ \\ ${ }^{1}$ Senior Resident, ${ }^{2}$ Professor and HOD, ${ }^{3}$ Associate Professor, Dept. of Pathology, Andaman \& Nicobar Islands Institute of \\ Medical Sciences, Port Blair, India \\ *Corresponding Author: Sampa Choudhury \\ Email: dr.sampa.choudhury@gmail.com
}

Received: $11^{\text {th }}$ May, 2018

Accepted: $19^{\text {th }}$ May, 2018

\begin{abstract}
Introduction: FNAC is an excellent modality for diagnosis of thyroid lesions because of its simplicity and cost effectiveness. Since the introduction of The Bethesda System for Reporting Thyroid Cytopathology (TBSRTC) in 2007, it has become a standardized, convenient and more informative system of thyroid reporting.

Aims: 1. To study cytological features of FNAC and categorization according to TBSRTC; 2 . To assess statistical analysis of FNAC in detecting malignant lesions.

Settings and Design: This is a cross-sectional study carried out in the Pathology Department from January 2015 to December 2017.

Materials and Methods: We interpreted 329 thyroid FNAC and categorized them according to TBSRTC. 75 cases are correlated histologically.

Statistical Analysis: Accuracy, specificity, sensitivity and predictive values.

Result: Distribution of different categories are as follows Non-diagnostic/unsatisfactory (ND/UNS)-8.5\%, Benign-85.2\%, Atypia of undetermined significance/follicular lesion of undetermined significance (AUS/FLUS)-0.6\%, Follicular neoplasm/suspicious for follicular neoplasm (FN/SFN)-2.4\%, Suspicious for malignancy (SFM)-1.5\% and malignant-1.8\%. The malignancy risk calculated from histopathological follow up of 75 cases is as follows: ND/UNS 0\%, Benign 6.9\%, FN/SFN 16.7\%, SFM 66.7\% and malignant $100 \%$. The positive predictive value, negative predictive value and accuracy of TBSRTC are $100 \%, 93.1 \%, 93.7 \%$ respectively.

Conclusion: The malignancy risk, accuracy, specificity and predictive values are consistent with other studies. Thus TBSRTC allows more standard reporting, specific diagnosis and understanding of terminology between pathologists and clinicians.
\end{abstract}

Keywords: FNAC, TBSRTC, Thyroid.

\section{Introduction}

Thyroid lesions are very common worldwide and fine needle aspiration cytology (FNAC) is the first choice in making a diagnosis of thyroid enlargement. It has become the standard modality in the evaluation of thyroid enlargement. Combined with radiological imaging, it gives a high degree of accuracy. However, because of lack of standardized system of reporting the terminologies and variation in criteria from one laboratory to another created confusion between clinician and cytopathologists and hindered a definite clinical management. To overcome this issue, in the year 2007, National Cancer Institute (NCI) organized a conference at Bethesda, Maryland. The meeting concluded with a consensus to use a standardized nomenclature for the interpretation of thyroid FNAC. This led to The Bethesda Thyroid Atlas Project and formed the framework for The Bethesda System for Reporting Thyroid Cytology (TBSRTC). ${ }^{1,2}$

TBSRTC recommends six categories of thyroid lesions with subcategories. Each category has an implied malignancy risk with rational clinical management.

In our study we have categorized the thyroid lesions according to TBSRTC and subsequently correlated histologically for statistical analysis and malignancy risk.

\section{Aims}

1. To study cytological features of FNAC and categorization according to TBSRTC.

2. To assess statistical analysis of FNAC in detecting malignant lesion.

\section{Materials and Methods}

This cross-sectional study was conducted in our institute from January 2015 to December 2017. All thyroid lesions subjected to thyroid FNAC irrespective of age and sex were included in our study. There were 329 thyroid FNAC. Smears of each case were stained with Hematoxylin \& Eosin, Giemsa and Papanicolaou stain. Cytological diagnoses of thyroid lesions were evaluated according to Bethesda system of reporting. The six categories of TBSRTC are as follows I. ND/UNS (non-diagnostic/ unsatisfactory), II. Benign, III. AUS/FLUS (atypia for undetermined significance or follicular lesion of undetermined significance), IV. FN/SFN (follicular neoplasm/ suspicious for follicular neoplasm), V. SFM (suspicious for malignancy), VI. Malignant. 
The histopathology reports were available for 75 cases. The malignancy risks of different categories were evaluated from cytohistological correlation. Other statistical analysis that includes sensitivity, specificity, accuracy, positive predictive value and negative predictive value were also obtained. Cases, which were reported either non-diagnostic or suspicious, were excluded and only benign (category II) and malignant (category VI) were included for statistical analysis.

\section{Results}

Total 329 thyroid FNAC including 57 ultrasound guided and 272 non-guided cases were performed over a period of 3years. The age range of patients was from 3 years to 80 years and the maximum number of patients (32\%) was in the age group of 31-40 years, with Female to Male ratio 11:1 [Fig. 1,2]. All cases were categorized according to TBSRTC. The most common cytological diagnostic category was benign cases (85.2\%) of which benign follicular nodule was in maximum number [Table 1].

Histopathology correlation was available in 75 cases. Malignancy risk of each category was assessed
[Table 2].

Among those 75 cases, there were three nondiagnostic (Category I), 58 benign (Category II), six suspicious for follicular neoplasm (category IV), three suspicious for malignancy (category V), and five malignant (Category VI) cases. There were no AUS/FLUS (Category III) cases. The histopathological findings were illustrated in a flow chart [Fig. 3].

Sixty-three cases of Category II and Category VI were assessed for statistical analysis. Out of 63 cases, 54 were true negative (both cytologically and histologically benign) and five were true positive (both cytologically and histologically malignant). And remaining four cases, which were cytologically colloid goiters, showed histologically papillary thyroid carcinoma in three cases and follicular carcinoma in one case. Therefore, those four cases were false negative. There was no false positive case. The sensitivity, specificity, positive predictive value (PPV), negative predictive value (NPV) and accuracy were calculated as $55.6 \%, 100 \%, 100 \%, 93.1 \%$ and $93.7 \%$ respectively [Table 4].

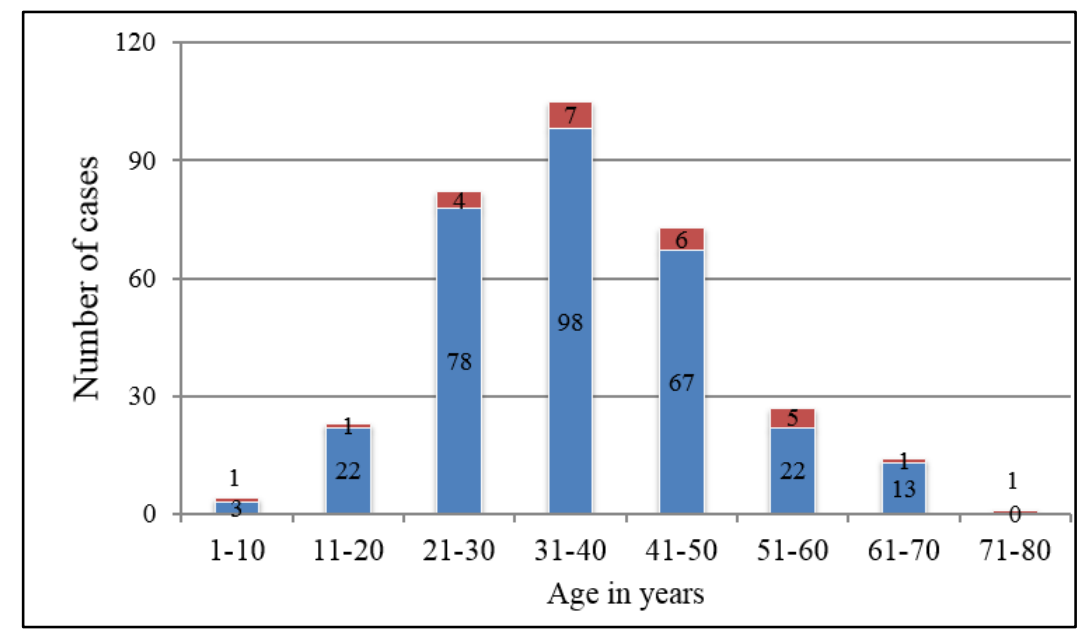

Fig. 1: Age and sex wise distribution

Fig. 2: Sex ratio

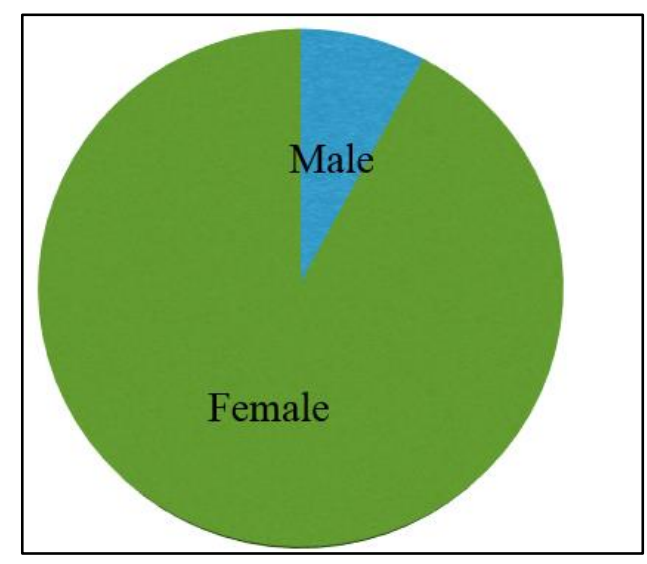




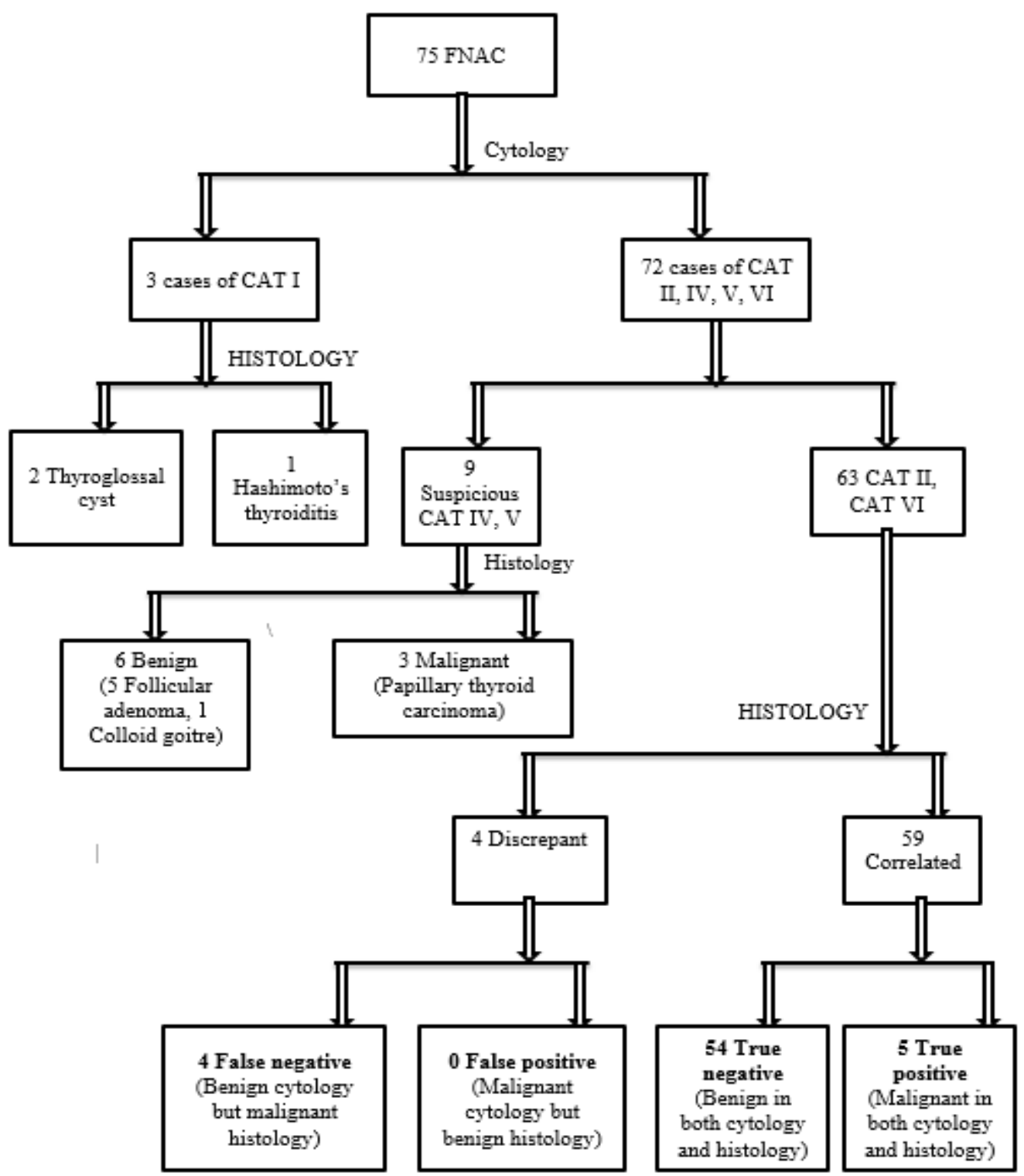

Fig. 3: Histopathological findings of thyroid lesions

*CAT- Category

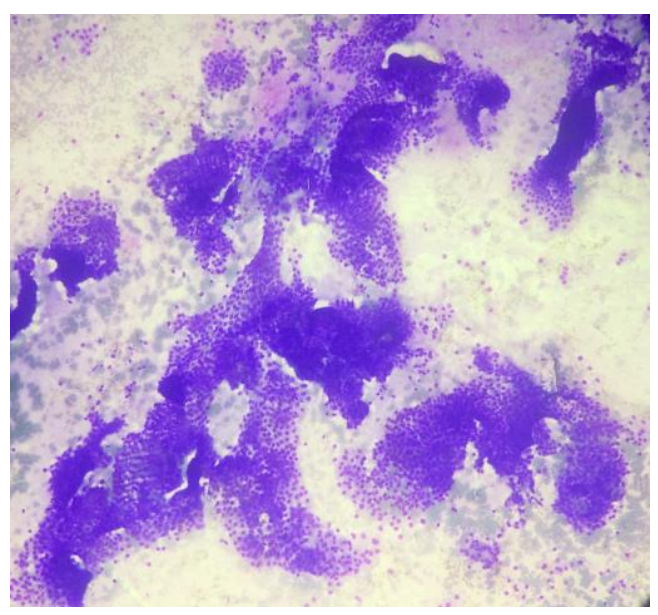

Fig. 4: Papillary thyroid carcinoma, Giemsa 10x

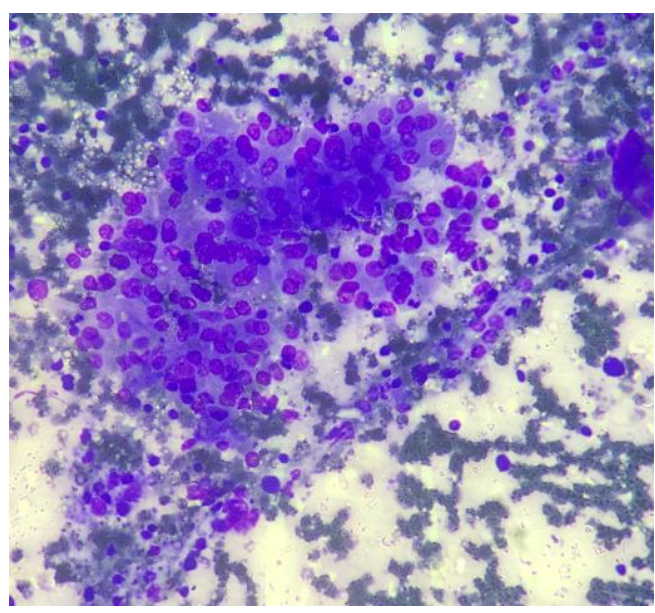

Fig. 5: Hashimoto's thyroiditis, Giemsa 40x 
Table 1: Distribution of thyroid lesions according to TBSRTC

\begin{tabular}{|c|c|c|c|}
\hline $\begin{array}{l}\text { Cytological } \\
\text { categories }\end{array}$ & Sub-categories & No. of cases & $\begin{array}{c}\text { Total no. } \\
\text { of cases } \\
(\%)\end{array}$ \\
\hline \multirow{3}{*}{ ND/UND } & Cyst fluid only & $08(2.4)$ & \multirow{3}{*}{$28(8.5)$} \\
\hline & Virtually acellular specimen & $14(4.3)$ & \\
\hline & Other (obscuring blood, clotting artifact etc.) & $06(1.8)$ & \\
\hline \multirow[t]{4}{*}{ Benign } & $\begin{array}{l}\text { Consistent with benign follicular nodule (includes colloid } \\
\text { nodule and adenomatoid nodule) }\end{array}$ & $189(57.5)$ & \multirow[t]{4}{*}{$280(85.2)$} \\
\hline & Consistent with lymphocytic (Hashimoto) thyroiditis & $88(26.8)$ & \\
\hline & Consistent with granulomatous (subacute) thyroiditis & $02(0.6)$ & \\
\hline & Others & $01(0.3)$ & \\
\hline AUS/FLUS & & 02 & 0.6 \\
\hline FN/SFN & & 08 & 2.4 \\
\hline \multirow[t]{5}{*}{ SFM } & Suspicious of papillary carcinoma & 04 & \multirow[t]{5}{*}{1.5} \\
\hline & Suspicious of medullary carcinoma & 01 & \\
\hline & Suspicious of metastatic carcinoma & & \\
\hline & Suspicious of lymphoma & & \\
\hline & Others & & \\
\hline \multirow[t]{6}{*}{ Malignant } & Papillary thyroid carcinoma & 06 & 1.8 \\
\hline & Medullary thyroid carcinoma & & \\
\hline & Undifferentiated (anaplastic) carcinoma & & \\
\hline & Squamous cell carcinoma with mixed features (specify) & & \\
\hline & Metastatic carcinoma & & \\
\hline & Non-Hodgkin lymphoma other & & \\
\hline Total cases & & 329 & 100 \\
\hline
\end{tabular}

Table 2: Malignancy risk of different categories

\begin{tabular}{|l|c|c|c|c|}
\hline \multirow{2}{*}{ FNAC } & \multicolumn{2}{|c|}{ Histopathology } & \multirow{2}{*}{ Total number of cases } & Malignancy risk (\%) \\
\cline { 2 - 3 } & Benign & Malignant & & 0 \\
\hline Non-diagnostic & 3 & 0 & 3 & 6.9 \\
\hline Benign & 54 & 4 & 58 & 16.7 \\
\hline SFN & 5 & 1 & 6 & 66.7 \\
\hline SFM & 1 & 2 & 3 & 100 \\
\hline Malignant & 0 & 5 & 5 & \\
\hline
\end{tabular}

Table 3: Comparison of malignancy risk with other studies

\begin{tabular}{|c|c|c|c|c|c|c|}
\hline $\begin{array}{l}\text { TBSRTC } \\
\text { Category }\end{array}$ & $\begin{array}{l}\text { Present } \\
\text { study }\end{array}$ & $\begin{array}{l}\text { Implied risk } \\
\text { of TBSRTC }\end{array}$ & $\begin{array}{c}\text { Yassa et } \\
\mathrm{al}^{8}\end{array}$ & $\begin{array}{c}\text { Naz et } \\
\text { al }^{9}\end{array}$ & $\begin{array}{l}\text { Hajmanoochehri } F \\
\text { and Rabiee } E^{13}\end{array}$ & $\underset{\text { al }^{14}}{\text { Yang et }}$ \\
\hline ND/UNS & 0 & $1-4$ & 10 & - & - & 10.7 \\
\hline Benign & 6.9 & $0-3$ & 0.3 & 11.1 & 6.9 & 0.7 \\
\hline FN/SFN & 16.7 & $15-30$ & 28 & 25 & 37 & 32.2 \\
\hline SM & 66.7 & $60-75$ & 60 & 100 & 81.2 & 64.8 \\
\hline Malignant & 100 & $97-99$ & 97 & 100 & 100 & 98.4 \\
\hline
\end{tabular}

Table 4: Statistical analysis of FNAC findings in detecting malignant lesions

\begin{tabular}{|l|c|}
\hline \multicolumn{1}{|c|}{ Parameters } & Percentages (\%) \\
\hline Sensitivity & 55.6 \\
\hline Specificity & 100 \\
\hline Accuracy & 93.7 \\
\hline Positive predictive value & 100 \\
\hline Negative predictive value & 93.1 \\
\hline
\end{tabular}


Table 5: Comparison of statistical analysis with other studies

\begin{tabular}{|c|c|c|c|c|c|c|}
\hline $\begin{array}{c}\text { Statistical } \\
\text { analysis }\end{array}$ & $\begin{array}{c}\text { Present } \\
\text { study }\end{array}$ & Naz et al & $\begin{array}{c}\text { Chebii et } \\
\mathbf{a l}^{\mathbf{1 0}}\end{array}$ & $\begin{array}{c}\text { Sharma } \\
\text { C et al } \mathbf{1}^{\mathbf{1 1}}\end{array}$ & $\begin{array}{c}\text { Bagga PK } \\
\text { and Mahajan } \\
\text { NC }^{\mathbf{1 2}}\end{array}$ & $\begin{array}{c}\text { Hajmanoochehri } \\
\text { F and Rabiee } \mathbf{E}^{\mathbf{1 3}}\end{array}$ \\
\hline Sensitivity & 55.6 & 64.3 & 54.5 & 89.5 & 66 & 95.2 \\
\hline Specificity & 100 & 85 & 96 & 98 & 100 & 68.4 \\
\hline $\begin{array}{c}\text { Positive } \\
\text { predictive } \\
\text { value }\end{array}$ & 100 & 56.3 & 66.7 & 84.6 & 100 & 83.3 \\
\hline $\begin{array}{c}\text { Negative } \\
\text { predictive } \\
\text { value }\end{array}$ & 93.1 & 88.9 & 93.5 & 98.6 & 96 & 89.6 \\
\hline Accuracy & 93.7 & 80.3 & 90.8 & 97 & 96.2 & 85.1 \\
\hline
\end{tabular}

\section{Discussion}

In our present study, we have categorized the cytology reports according to TBSRTC and correlated histologically for malignancy risk and statistical analysis. The maximum number of the cases was in the age group of 31-40 years of age with the female predominance. These findings were comparable with Renuka IV et al, ${ }^{3}$ Deshpande AH et $\mathrm{al}^{4}$ and Agrawal R et al. ${ }^{5}$

Among the six categories of TBSRTC, the benign cases reported in $85.2 \%$ followed by ND/UNS $(8.5 \%)$ and other categories. The number of malignant cases $(1.8 \%)$ was low in our study. These findings were similar to the findings of Agrawal et al, ${ }^{5}$ Mondal SK et $\mathrm{al}^{6}$ and Laishram RS et $\mathrm{al}^{7}$ The large proportion of benign cases and relatively low percentage of malignant cases can be explained by the fact that our institute is the only general hospital catering to the entire population and gets cases with or without referral. Studies carried out in referral centers show a higher number of malignancies. ${ }^{8,16}$

The FNAC smears which showed less number of follicular cells, obscuring blood, cystic fluid and cyst macrophages were reported as Nondiagnostic/unsatisfactory and repeat aspiration under USG guidance was advised. Inadequate or unsatisfactory smears can be because of sclerotic or calcified lesions or more commonly when there are cystic degeneration or necrosis. ${ }^{5,12}$ The percentage of ND/UNS should be below $10 \%$ according to some authors. ${ }^{14,15}$ This category contributes $8.5 \%$ cases in our study, which is found closer to the findings of Mondal SK et al, ${ }^{6}$ Laishram RS et $\mathrm{al}^{7}$ and Yassa L et al. ${ }^{8}$

Cytohistological correlation was done in 75 cases. Malignancy risk of different categories was calculated and the obtained percentages were close to the implied risk of TBSRTC and other studies with some differences [Table 3]. ${ }^{8,9,13,14}$ Our results show lower percentage $(0 \%)$ in ND/UNS category and little bit higher percentage $(6.9 \%)$ in benign category compared to implied risk of TBSRTC and other studies. Moreover, risk cannot be evaluated in AUS/FLUS category. The probable explanation of those differences TBSRTC recommends proper clinical management and can be because of majority of the surgically removed specimens were cytologically reported as either suspicious for malignancy or malignant. Most of the benign, ND/UNS and AUS/FLUS cases were not surgically removed. Therefore, the denominators of those cases were less and gave rise to those differences in the findings.

We observed high specificity, PPV, NPV and accuracy values, which are comparable with the findings of other studies [Table 4,5]. The sensitivity of thyroid FNAC was observed to be $55.6 \%$, which is similar to Naz $\mathrm{S}$ et al, ${ }^{9}$ Chebii $\mathrm{K}$ et $\mathrm{al}^{10}$ and Bagga PK and Mahajan NC. ${ }^{12}$ On the contrary, some authors claimed high sensitivity of FNAC diagnosis. ${ }^{11,13}$ As sensitivity is inversely proportional to the number of false negative cases, our four false negative cases which were cytologically missed for malignancy has lowered the sensitivity. Sometimes, FNAC may yield less follicular cells and the typical nuclear features of papillary carcinoma of thyroid may not be obvious which leads to the misdiagnosis and raise the false negative value. Another reason may be those unguided four false negative cases might not aspirated from the representative areas as FNAC is a blind procedure. Moreover, the non-diagnostic and suspicious cases were excluded and only the benign (category II) and malignant (category VI) cases were assessed for analysis. These may be the probable reasons behind low sensitivity of our study as compared to some authors.

It may be noted that our institute is a newly established institute and we have faced many limitations and obstacles, simultaneously. The major limitations of our study are less number of cases for cytohistological correlation and clinical correlations could not be evaluated for every case. To overcome those limitations more studies on larger populations with clinical, biochemical and radiological details should be encouraged.

\section{Conclusion}

FNAC is simple, minimally invasive, cost effective and safe technique for evaluation of thyroid swellings. Thyroid cytology reporting in accordance with provides a better communication between clinicians and 
pathologists. The cytohistological correlation is a quality assurance method through which pathologists can assess the false positive and false negative results and improve their diagnostic performance. In our study, we have good cytohistological correlation with high specificity, accuracy and predictive values which once again proves thyroid FNAC a reliable primary investigation in evaluating thyroid nodules.

\section{Financial Support: Nil.}

Conflict of Interest: There is no conflict of interest.

\section{References}

1. Baloch ZW, Livolsi VA, Asa SL, Rosai J, Merino MJ, Randolph G et al. Diagnostic terminology and morphologic criteria for cytologic diagnosis of thyroid lesions: A symposia of the national cancer institute thyroid fine-needle aspiration state of the science conference. Diagn Cytopathol. 2008;36:425-37.

2. Cibas ES, Ali SZ. The Bethesda system for reporting thyroid cytopathology. Am J Cain Pathol. 2009;132:65865.

3. Renuka IV, Bala GS, Aparna C, Kumari R, Sumalatha K. The Bethesda system for reporting thyroid cytopathology: Interpretation and guidelines in surgical treatment. Indian J Otolaryngol Head Neck Surg. 2012;64(4):305-11.

4. Deshpande AH, Nayak SP, Gaikwad ST, Bundle MM, Parate SN, Lele VR et al. Fine needle aspiration cytology as an initial modality for the investigation of thyroid enlargement: A study 2818 cases. Journal of Academy of Medical Sciences. 2004;32(3):25-9.

5. Agrawal R, Saxena M, Kumar P. A study of fine needle aspiration cytology of thyroid lesions with histopathological correlation. Indian J Pathol Onco. 2015;2(4):277-83

6. Mondal SK, Sinha A, Basak B, Roy DN, Sinha SK. The Bethesda system for reporting thyroid fine needle aspirates: A cytologic study with histologic follow-up. $J$ Cytol. 2013;30(2):94-99.

7. Laishram RS, Zothanmawii T, Joute Z, Yasung P, Debnath K. The Bethesda system of reporting thyroid fine needle aspirates: A 2 year cytologic study in a tertiary care institute. J Med Soc. 2017;31:3-7.
8. Yassa L, Cibas ES, Benson CB, Frates MC, Doubilet PM, Gawande AA et al. Long term assessment of a multidisciplinary approach to thyroid nodule diagnostic evaluation. Cancer. 2007;111:508-16.

9. Naz S, Hashmi AA, Khurshid A, Faridi N, Edhi MM, Kamal A et al. Diagnostic accuracy of Bethesda system for reporting thyroid cytopathology: an institutional perspective. International Archives of Medicine. 2014;7:46-50.

10. Chebii K, Bargoria F, Alwala D. Cytohistological correlations of thyroid masses findings at the MOI teaching and referral hospital, Kenya. IJIRR. 2016;3(12):3322-7.

11. Sharma C. Diagnostic accuracy of the fine needle aspiration cytology of thyroid and evaluation of discordant cases. Journal of the Egyptian National Cancer Institute. 2015;27:147-53.

12. Bagga PK, Mahajan NC. Fine needle aspiration cytology of thyroid swellings: how useful and accurate is it? Indian J Cancer. 2010;47(4):437-42.

13. Hajmanoochehri F, Rabiee E. FNAC accuracy in diagnosis of thyroid neoplasms considering all diagnostic categories of the Bethesda reporting system: A singleinstitute experience. J Cytol. 2015;32:238-43.

14. Yang J, Schnadig V, Logrono R, Wasserman PG. Fineneedle aspiration of thyroid nodules: A study of 4703 patients with histologic and clinical corrections. Cancer. 2007; 111:306-15.

15. Ali SZ, Thyroid cytopathology: Bethesda and beyond. Acta Cytol. 2011;55:4-12.

16. Jo VY, Stelow EB, Dustin SM, Hanley KZ. Malignancy risk for fine-needle aspiration of thyroid lesions according to the Bethesda system for reporting thyroid cytopathology. Am J Cain Pathol. 2010;134:450-6.

How to cite this article: Choudhury S, Deshpande A.H, Gargade C. B. The Bethesda system for reportingthyroid FNAC: A cytohistological correlation in anewly established institute. Indian $\mathbf{J}$ Pathol Oncol.2018;5(4):650-655. 